\title{
High power impulse magnetron sputtering and related discharges: scalable plasma sources for plasma-based ion implantation and deposition
}

\author{
André Anders \\ Lawrence Berkeley National Laboratory, Berkeley, California, USA \\ Content of this review to be presented as Invited Talk on Sept. 9, 2009, at the \\ $10^{\text {th }}$ International Workshop on Plasma Based Ion Implantation and Deposition \\ and submitted for peer review to \\ Surface and Coatings Technology \\ Sept. 1, 2009
}

\section{ACKNOWLEDGMENT}

This work was supported by the U.S. Department of Energy, Initiatives for Proliferation Prevention, under Contract No. DE-AC02-05CH11231 with the Lawrence Berkeley National Laboratory.

\section{DISCLAIMER}

This document was prepared as an account of work sponsored by the United States Government. While this document is believed to contain correct information, neither the United States Government nor any agency thereof, nor The Regents of the University of California, nor any of their employees, makes any warranty, express or implied, or assumes any legal responsibility for the accuracy, completeness, or usefulness of any information, apparatus, product, or process disclosed, or represents that its use would not infringe privately owned rights. Reference herein to any specific commercial product, process, or service by its trade name, trademark, manufacturer, or otherwise, does not necessarily constitute or imply its endorsement, recommendation, or favoring by the United States Government or any agency thereof, or The Regents of the University of California. The views and opinions of authors expressed herein do not necessarily state or reflect those of the United States Government or any agency thereof or The Regents of the University of California. 


\title{
High power impulse magnetron sputtering and related discharges: scalable plasma sources for plasma-based ion implantation and deposition
}

\section{André Anders}

Lawrence Berkeley National Laboratory, Berkeley, California, USA

\begin{abstract}
High power impulse magnetron sputtering (HIPIMS) and related self-sputtering techniques are reviewed from a viewpoint of plasma-based ion implantation and deposition (PBII\&D). HIPIMS combines the classical, scalable sputtering technology with pulsed power, which is an elegant way of ionizing the sputtered atoms. Related approaches, such as sustained self-sputtering, are also considered. The resulting intense flux of ions to the substrate consists of a mixture of metal and gas ions when using a process gas, or of metal ions only when using 'gasless' or pure self-sputtering. In many respects, processing with HIPIMS plasmas is similar to processing with filtered cathodic arc plasmas, though the former is easier to scale to large areas. Both ion implantation and etching (high bias voltage, without deposition) and thin film deposition (low bias, or bias of low duty cycle) have been demonstrated.
\end{abstract}

\section{Introduction: Plasma sources for PBII\&D}

Plasma-based ion implantation and deposition (PBII\&D) is a family of surface modification and thin film deposition techniques overlapping with other plasma-based technologies known under various other names. The basic idea is to immerse a substrate in a plasma and apply a usually rather high voltage to it; as a result, a high voltage sheath forms between plasma and substrate, enabling controlled acceleration of plasma ions after they cross the plasma-sheath boundary (sheath edge). Depending on the voltage amplitude and the character of the plasma, ion implantation and/or deposition occurs [1].

An early form, or predecessor, of PBII\&D is ion plating where metal vapor is partially ionized and the growing metal film is subject of ion bombardment [2]. Instead of trying to ionize atoms from a metal evaporation source, metal plasma can be readily produced using high-current pulsed arc or spark discharges in vacuum [3]. These early, pioneering attempts inspired the much-cited work by Conrad and coworkers [4] who used non-condensable (not film-forming) nitrogen plasma for surface modification: the implantation of nitrogen facilitated the formation of nitrides in the surface layer with the well-known advantageous features of enhanced hardness and improved wear and corrosion resistance.

Without further reviewing the many papers that appeared on the subject, one can see that the plasma sources can be generally classified in gaseous and those leading to film growth (condensable, usually containing metal or carbon ions). Gaseous plasma can be further classified in noble and reactive gases, while metal plasmas can be quite different in their properties, especially in terms of ion charge states and ion energy distribution functions. Examples of gas plasma sources include radio-frequency (RF) sources [4-5] and distributed electron cyclotron resonance microwave (DECR) sources [6]. 
For years, pulsed vacuum arc plasma sources have been the subject of research in the field of PBII\&D due to the relative simplicity of producing flows of fully ionized plasma with multiply charged ions. Bias pulses, or burst thereof, can be synchronized with pulsed plasma production; and so both ion implantation and deposition can be tuned [7-8]. Undesired macroparticles can be removed using plasma filters, and the technique is sometimes named metal ion plasma immersion ion implantation and deposition (MePIIID) [8]. Besides the macroparticle issue, cathodic arc plasmas are also known to be fluctuating ('noisy') and difficult to scale to large areas due to the plasma production at small, non-stationary cathode spots. Therefore, there is a need for scale, well reproducible plasmas for ion-based surface modification and film deposition.

With the advent of high power impulse magnetron sputtering (HIPIMS) in the late 1990s [9], a new development emerged that followed the MePIIID techniques in many respects but the means of plasma production. HIPIMS is an advanced form of ionized sputtering, or more generally speaking, ionized physical vapor deposition (i-PVD), which was originally pioneered for, and driven by the need to manufacture multi-level integrated circuits with metalized trenches and vias [10-11].

In the following section, HIPIMS and related discharge plasmas are considered: they greatly expand the range of available plasma sources for PBII\&D processing.

\section{HIPIMS and related plasmas}

As the letter " $M$ " in the name 'HIPIMS' suggest, and in contrast to pulsed cathodic arc discharges, the discharges under consideration make use of a magnetron, a device widely used in PVD. The basic idea is to use the same magnetron hardware but apply the power in high current pulses that greatly exceed the average power. A special power supply is needed, and it will greatly determine the system's features. The powerful 'abuse' of the magnetron results in the formation of a dense plasma adjacent to the target. Part of the plasma drifts to the substrate where PBII\&D processing can occur. Fig. 1 shows a generic setup, the details of which will be explained later in this section.

As the sputtered atoms travel through the dense plasma, the likelihood for an ionizing collision is quite high, vastly higher than in a conventional magnetron discharge, where by far most atoms travel without collisions to the substrate, walls, shields, or other components. To facilitate high current pulses, the target needs to have good electrical conductivity, and therefore HIPIMS is generally limited to metal targets. The first ionization energy of practically all metals is lower than the first ionization energy of gases, which helps that the degree of ionization of the sputtered atoms can readily exceed the degree of ionization usually observed with the sputtering gas plasma.

The newly formed ions of the target material will participate in the discharge and sputtering process, i.e. self-sputtering occurs. Interestingly, self-sputtering is known for much longer than the HIPIMS technique [12-13], and indeed, self-sputtering can be selfsustained in the sense that once started with some gas, the gas is no longer needed and the discharge can be operated exclusively with plasma of the target material. This, however, works only for a small group of target materials, namely those that show a high selfsputtering yield. Most prominently among them is copper, and many experimental reports deal with copper.

Sustained self-sputtering plasma can be considered as one possible source for PBII\&D. One option is to use the plasma in DC mode; the gas supply can be closed after 
starting. In order to not destroy the magnetron by exceeding the allowable power, the average power needs to be carefully selected in a compromise: on the one hand one has to observe the limitations given by target and magnet cooling capabilities, and on the other hand one wants high power that leads to a high degree of ionization of the large flux of sputtered neutrals.

Another option is to not to use DC but to provide the power in pulses such that during the pulse the power can be high and the system is allowed to cool in between pulses. This was recently done with medium-frequency pulses where the plasma of the previous pulse facilitates the triggering of the following self-sputtering pulse. Given the high duty cycle of $80 \%$ or greater, the power density on the target was extremely high, exceeding $500 \mathrm{~W} / \mathrm{cm}^{2}$ [14].

Reducing the duty cycle allows us to go higher in the power density during the pulse. In the special case of a constant voltage power supply, i.e. one based on very large capacitive energy storage like the SPIK 2000A pulser by Melec, the phenomenon of selfsputtering runaway and saturation can be readily observed [15]. Runway is driven by a positive feedback: more ions cause more sputtering, more sputtering delivers more atoms that can be ionized, which occurs when enough power is supplied, and more ions in turn cause even more sputtering. The condition for self-sputtering runaway can be expressed by the parameter $\Pi[12,15-16]$,

$$
\Pi \equiv \alpha \beta \gamma_{S S}>1
$$

where $\alpha$ is the probability of ionization of a sputtered atom, $\beta$ is the probability of return of the newly formed ion to the target, and $\gamma_{s S}$ is the self-sputtering yield. As runaway proceeds in a matter of $\sim 10 \mu \mathrm{s}$, the fluxes of atoms and ions from the target zone to the substrate and other components increase, too. Those fluxes are highly desirable and needed for processes like PBII\&D; they represent 'losses' to the selfsputtering process and dampen the runaway. When the pulse is long enough, typically exceeding $100 \mu$ s, a new, high-power steady-state can establish itself, where $\Pi=1$.

The process of self-sputtering with runaway to a high power level can be readily started when process gas is present (often argon or a mixture containing argon), but it is also possible to avoid the use of any gas and work in vacuum if a synchronized, triggering plasma is supplied to the magnetron. Such triggering 'plasma puff' could be made using pulsed laser ablation from a laser target placed near the sputtering target, or one could use a very short ( $10 \mu \mathrm{s})$ vacuum arc. The latter has been demonstrated for 'gasless' HIPIMS [16-17].

Many target materials do not have a self-sputtering yield high enough to deliver a large flux of atoms for target voltage less than to $1000 \mathrm{~V}$, and therefore self-sputtering cannot be sustained by itself $(\Pi<1)$ but requires the presence of some process gas. For example, the atoms of the application-relevant group of transition metals including $\mathrm{Ti}$, $\mathrm{Cr}, \mathrm{Nb}, \mathrm{Hf}, \mathrm{Zr}$, and Y show high ionization under HIPIMS conditions but cannot operate in 'gasless' HIPIMS or DC self-sputtering mode. On the flipside, because less atoms are available than with high-yield targets, the electrons in the HIPIMS plasma are less cooled by inelastic collisions, and the resulting relatively higher electron temperature enables the production of a significant fraction of doubly charged ions [18-20], and small fractions of even higher charged ions [20-21]. As it is typical for PBII\&D, a higher charge state, $Q$, lead to higher ion kinetic energy upon impact on the surface, governed by the relation 


$$
E_{i, k i n}=E_{0}+Q e V_{\text {sheath }},
$$

where $E_{0}$ is the kinetic energy of ions in the plasma before acceleration in the sheath, $e$ is the elementary charge, and $V_{\text {sheath }}$ is the sheath voltage, which is approximately given by the applied bias.

Graphite as target material requires special mentioning. It would be highly desirable to produce diamond-like carbon (DLC) films, and preferably the high-density kind with very high $\mathrm{sp}^{3} / \mathrm{sp}^{2}$ bond ratio, known as tetrahedral amorphous carbon or ta-C [22]. It turns out that the self-sputtering yield of carbon is exceptionally low and stays less than unity for all energies, hence sustained self-sputtering is not possible. Hard carbon films have been made by HIPIMS [23] though the films showed defects and did not reach the quality obtained by filtered cathodic arc deposition.

After considering DC and pulsed self-sputtering discharges, it is time to move on to the typical HIPIMS process as introduced by the much-cited work of Kouznetsov and co-workers [9]. In this early work, $50 \mu$ s pulses of rather high power of about $600 \mathrm{~kW}$ were applied to a copper target of $15 \mathrm{~cm}$ diameter (nominal peak power $>3 \mathrm{~kW} / \mathrm{cm}^{2}$ ). Short pulses of less than $100 \mu$ s were, and still are, popular because short pulses are known to be less susceptible to arcing of the target. In those short times, the current has generally not reached any steady-state but usually shows a steep rise: the current pulse shape is more or less triangular. Many researchers used this feature and picked the peak current as a parameter that can be correlated with plasma properties, like the degree of ionization, and film properties, like the preferred texture and stress. However, the peak current depends on many factors, like pressure, magnetic field of the magnetron, applied voltage, etc. and is therefore not ideal for comparing various systems. Especially when including longer pulses, the complete current-voltage-time characteristic should be presented [15].

Coming back to the typical short-pulse HIPIMS, the plasma is used with high substrate bias (-1 kV or more) for ion implantation, sputtering, and tailoring of mixed interfaces [24-25], as well as for ion-assisted film growth, where of course the bias is much lower, typically $100 \mathrm{~V}$ or less. Besides for metallization involving $\mathrm{Cu}$ [9], Ag [26], and Ta [27], (short-pulse) HIPIMS is mainly used for the fabrication of well adherent and dense compound films, nanocomposites, and nanolaminates. Material systems include $\mathrm{TiO}_{2}$ [28-30], $\mathrm{ZnO}$ [31], $\mathrm{Al}_{2} \mathrm{O}_{3}$ [32], $\mathrm{CrN}$ [33-35], TiAlCN/VCN [36], $\mathrm{ZrO}_{2}$ [37], ITO and AZO [38].

Finally, there is also the possibility of using relatively long pulses of high but not extreme power density, where the risk of arcing is mitigated by using different power levels during each pulse. This approach has been dubbed modulated pulsed power (MPPТM) sputtering and is enabled by a special power supply that allows the operator to freely program the voltage and resulting power levels [39]. Different magnetrons, materials, and pressure situations can be accommodated by stepwise increase of power. Empirically optimized specifics can be stored as recipes for processing. It should be noted that the reactive gas, like nitrogen, is significantly ionized in those long pulses, which is beneficial for the formation of compound films [40].

A compilation is provided in Table 1 to summarize and compare the various approaches to plasma generation using magnetrons. 
Table 1 Summary of magnetron plasma types, their features, and applicability to PBII\&D; values are for orientation only and may vary depending on target material, gas type, magnetic field, balancing, etc.

\begin{tabular}{|c|c|c|c|c|c|c|c|}
\hline & $\begin{array}{l}\text { typical nominal } \\
\text { (peak) power } \\
\text { density at target }\end{array}$ & $\begin{array}{l}\text { typical } \\
\text { duration of } \\
\text { pulse }\end{array}$ & $\begin{array}{l}\text { typical } \\
\text { pulse } \\
\text { repetition } \\
\text { rate }\end{array}$ & $\begin{array}{l}\text { degree of } \\
\text { ionization }\end{array}$ & plasma composition & comments & $\begin{array}{l}\text { representative } \\
\text { references }\end{array}$ \\
\hline $\begin{array}{l}\text { conventional } \\
\text { magnetron } \\
\text { sputtering plasma }\end{array}$ & $1-10 \mathrm{~W} / \mathrm{cm}^{2}$ & $\begin{array}{l}\text { minutes to } \\
\text { hours (whole } \\
\text { process) }\end{array}$ & $\mathrm{n} / \mathrm{a}$ & $\begin{array}{l}\text { very low } \\
(\sim 1 \%)\end{array}$ & $\begin{array}{l}\text { noble gas ions } \\
\text { (often } \mathrm{Ar}^{+} \text {), and of } \\
\text { the reactive gas, if } \\
\text { applicable }\end{array}$ & $\begin{array}{l}\text { effects of particle bombardment on film } \\
\text { properties are dominated by energetic neutrals, } \\
\text { not ions, hence bias is of limited effectiveness; } \\
\text { ion effects are greater with unbalanced } \\
\text { magnetrons }\end{array}$ & [41-43] \\
\hline $\begin{array}{l}\text { magnetron } \\
\text { sputtering with } \\
\text { RF post ionization } \\
\text { plasma }\end{array}$ & $\begin{array}{l}10 \mathrm{~W} / \mathrm{cm}^{2} \text { plus } \\
\mathrm{RF} \text { ionization in } \\
\text { volume } \\
>1 \mathrm{~W} / \mathrm{cm}^{3}\end{array}$ & $\begin{array}{l}\text { seconds to } \\
\text { minutes } \\
\text { (whole } \\
\text { process) }\end{array}$ & $\mathrm{n} / \mathrm{a}$ & $\begin{array}{l}\text { varies, metal } \\
\text { significantly } \\
\text { ionized }\end{array}$ & $\begin{array}{l}\text { mixture of noble gas } \\
\text { and metal plasma }\end{array}$ & $\begin{array}{l}\text { high gas pressure used to slow sputtered atoms, } \\
\text { thereby increasing their ionization probability; } \\
\text { developed for trench and via metallization: } \\
\text { relying on bias for optimization of features }\end{array}$ & {$[10,44-46]$} \\
\hline $\begin{array}{l}\text { DC self- } \\
\text { sputtering plasma }\end{array}$ & $100 \mathrm{~W} / \mathrm{cm}^{2}$ & $\begin{array}{l}\text { minutes to } \\
\text { hours (whole } \\
\text { process) }\end{array}$ & $\mathrm{n} / \mathrm{a}$ & $\begin{array}{l}\text { high, may } \\
\text { exceed 50\% }\end{array}$ & $\begin{array}{l}\text { pure metal after } \\
\text { shutoff of gas }\end{array}$ & $\begin{array}{l}\text { works only for very few target materials of high } \\
\text { yield, primarily } \mathrm{Cu} \text {, gas used for initial start }\end{array}$ & $\begin{array}{l}{[12-13,47-} \\
48]\end{array}$ \\
\hline $\begin{array}{l}\text { MF self- } \\
\text { sputtering plasma }\end{array}$ & $500 \mathrm{~W} / \mathrm{cm}^{2}$ & $\begin{array}{l}10 \mu \text { s, duty } \\
\text { cycle } 80 \%\end{array}$ & $60-90 \mathrm{kHz}$ & $\begin{array}{l}\text { high, may } \\
\text { exceed 50\% }\end{array}$ & $\begin{array}{l}\text { pure metal after } \\
\text { shutoff of gas }\end{array}$ & $\begin{array}{l}\text { works only for very few target materials of high } \\
\text { yield, primarily Cu, gas used for initial start }\end{array}$ & [14] \\
\hline $\begin{array}{l}\text { Typical } \\
\text { (relatively short- } \\
\text { pulse) HIPIMS } \\
\text { plasma }\end{array}$ & $1-5 \mathrm{~kW} / \mathrm{cm}^{2}$ & $10-100 \mu \mathrm{s}$ & $\begin{array}{l}0.05-10 \\
\mathrm{kHz}\end{array}$ & $\begin{array}{l}\text { strongly } \\
\text { increasing } \\
\text { within each } \\
\text { pulse }\end{array}$ & $\begin{array}{l}\text { initially gas } \\
\text { dominated; later in } \\
\text { pulse metal } \\
\text { dominated }\end{array}$ & $\begin{array}{l}\text { current typically still rising during each pulse; } \\
\text { peak current often correlated with plasma and } \\
\text { film parameters; most HIPIMS research uses } \\
\text { short pulses to reduce the risk of arcing }\end{array}$ & $\begin{array}{l}{[9,18,27-28} \\
32,35,38 \\
49]\end{array}$ \\
\hline $\begin{array}{l}\text { HIPIMS runaway } \\
\text { plasma }\end{array}$ & $1-5 \mathrm{~kW} / \mathrm{cm}^{2}$ & $100-1000 \mu \mathrm{s}$ & $0.01-1 \mathrm{kHz}$ & $\begin{array}{l}\text { several } 10 \% \text {, } \\
\text { may exceed } \\
50 \%\end{array}$ & $\begin{array}{l}\text { metal ion dominated } \\
\text { (apart from the } \\
\text { initial stage of each } \\
\text { pulse) }\end{array}$ & $\begin{array}{l}\text { single charged for high yield material, } \\
\text { significant doubly charged for low yield } \\
\text { transition metals, most obvious when using a } \\
\text { constant voltage power supply }\end{array}$ & [15-16] \\
\hline $\begin{array}{l}\text { gasless HIPIMS } \\
\text { plasma }\end{array}$ & $1-5 \mathrm{~kW} / \mathrm{cm}^{2}$ & $100-1000 \mu s$ & $0.01-1 \mathrm{kHz}$ & $\begin{array}{l}\text { high, may } \\
\text { exceed 50\% }\end{array}$ & pure metal & $\begin{array}{l}\text { needs short pulse arc or equivalent trigger } \\
\text { plasma; works only for very few target materials } \\
\text { of high yield }\end{array}$ & [16-17] \\
\hline $\begin{array}{l}\text { Modulated Pulsed } \\
\text { Power (MPPTM) } \\
\text { magnetron plasma }\end{array}$ & $100-500 \mathrm{~W} / \mathrm{cm}^{2}$ & $1-5 \mathrm{~ms}$ & $\begin{array}{l}0.01-0.5 \\
\mathrm{kHz}\end{array}$ & $\begin{array}{l}\text { modest in initial } \\
\text { phase(s), high in } \\
\text { later phase(s) } \\
\text { during each } \\
\text { pulse }\end{array}$ & $\begin{array}{l}\text { metal dominated; } \\
\text { may contain a high } \\
\text { fraction of reactive } \\
\text { gas ions when } \\
\text { applicable }\end{array}$ & $\begin{array}{l}\text { long pulses at modest power density by HIPIMS } \\
\text { standards; each pulse has two or more voltage } \\
\text { and power levels }\end{array}$ & [39-40] \\
\hline
\end{tabular}




\section{Discussion and concluding remarks}

There are many reasons why magnetron-based plasma sources are of concern to the PBII\&D community. Most importantly, they represent a class of sources delivering fluxes of ions with very good reproducibility and offering the possibility of scaling to industrial size compatible with existing batch and in-line coaters. Of course, as the targets are scaled to larger size, usually rectangular targets of up to $1 \mathrm{~m}$ length, or comparable, cylindrical, rotating targets, the pulse power needs to scale with the active or 'racetrack' area (the racetrack area is the area where the magnetic field lines are essentially parallel to the target surface and where the most intense sputtering occurs). For such large targets, the peak power needs to be in the $1 \mathrm{MW}$ region, and in some cases even in the $10 \mathrm{MW}$ region, to deliver comparable plasma parameters as demonstrated in the smaller research facilities. Fortunately, suitable HIPIMS power supplies with sophisticated arc handling already have become available, thereby enabling the scaling to active target areas of about $10^{4} \mathrm{~cm}^{2}$. Scaling to even larger magnetrons, as used in large area glass and web coatings (length $3.5 \mathrm{~m}$, active area $>30,000 \mathrm{~cm}^{2}$ ), remains to be shown.

Compared to other sources of condensable plasma, like laser ablation plasma and (filtered) cathodic arc plasma, HIPIMS plasmas are generally characterized by a high fraction of singly charged ions, which is especially true for the materials of high sputtering yield. Therefore, another benefit of using HIPIMS (or related) plasmas is monoenergetic processing, giving more precision to the tailoring of interfaces and film textures.

It should be emphasized that most of the findings for PBII\&D with cathodic arc plasmas are applicable to PBII\&D when using HIPIMS and related plasmas. For example, the issue of stress generation and relief by energetic particle bombardment [5051] applies in the same way. However, there are also marked differences. HIPIMS plasmas have generally a much higher accompanying flux of neutrals than cathodic arc sources. This points in the direction that HIPIMS plasmas are more suitable for the deposition part of PBII\&D than the implantation part, which is indeed reflected in the literature reviewed here. Furthermore, pulsed arc plasmas show distinctly higher ion charge states at the beginning of each pulse [52] whereas HIPIMS plasmas are usually gas-dominated at the beginning of each pulse [20]. Therefore, surface processing with those pulsed plasmas should be expected to be quite dependent on the type of plasma generation scheme.

\section{Acknowledgments}

This work was supported in part by an SBIR contract with Acree Technologies, Inc., and in part by the Assistant Secretary for Energy Efficiency and Renewable Energy, Office of Building Technology, of the U.S. Department of Energy, and under Contract No. DE-AC02-05CH11231. 


\section{References}

[1] A. Anders (Ed.), Handbook of Plasma Immersion Ion Implantation and Deposition, Wiley, New York, 2000.

[2] D.M. Mattox, J. Vac. Sci. Technol. 10 (1973) 47.

[3] R.J. Adler, S.T. Picraux, Nucl. Instrum. Meth. Phys. Res. B 6 (1985) 123.

[4] J.R. Conrad, J.L. Radtke, R.A. Dodd, F.J. Worzala, N.C. Tran, J. Appl. Phys. 62 (1987) 4591.

[5] S.Y. Wang, P.K. Chu, B.Y. Tang, X.C. Zeng, Y.B. Chen, X.F. Wang, Surf. Coat. Technol. 93 (1997) 309.

[6] F. Le Cœur, T. Lagarde, J. Pelletier, Y. Arnal, R. Burke, Rev. Sci. Instrum. 69 (1998) 831.

[7] I.G. Brown, X. Godechot, K.M. Yu, Appl. Phys. Lett. 58 (1991) 1392.

[8] A. Anders, Surf. Coat. Technol. 93 (1997) 157.

[9] V. Kouznetsov, K. Macak, J.M. Schneider, U. Helmersson, I. Petrov, Surf. Coat. Technol. 122 (1999) 290.

[10] S.R. Rossnagel, J. Hopwood, J. Vac. Sci. Technol. B 12 (1994) 449.

[11] J.A. Hopwood (Ed.), Ionized Physical Vapor Deposition, Academic Press, San Diego, CA, 2000.

[12] N. Hosokawa, T. Tsukada, H. Kitahara, Proc. 8th Int. Vacuum Congress, Le Vide, Cannes, France, 1980, p. 11.

[13] W.M. Posadowski, Z. Radzimski, J. Vac. Sci. Technol. A 11 (1993) 2980.

[14] A. Wiatrowski, W.M. Posadowski, Z.J. Radzimski, J. Vacuum Sci. Technol. A 26 (2008) 1277.

[15] A. Anders, J. Andersson, A. Ehiasarian, J. Appl. Phys. 102 (2007) 113303.

[16] J. Andersson, A. Anders, Phys. Rev. Lett. 102 (2009) 045003.

[17] J. Andersson, A. Anders, Appl. Phys. Lett. 92 (2008) 221503.

[18] A.P. Ehiasarian, R. New, W.-D. Münz, L. Hultman, U. Helmersson, V. Kouznetsov, Vacuum 65 (2002) 147.

[19] J. Bohlmark, M. Lattemann, J.T. Gudmundsson, A.P. Ehiasarian, Y. Aranda Gonzalvo, N. Brenning, U. Helmersson, Thin Solid Films 515 (2006) 1522.

[20] E. Oks, A. Anders, J. Appl. Phys. 105 (2009) 093304.

[21] J. Andersson, A.P. Ehiasarian, A. Anders, Appl. Phys. Lett. 93 (2008) 071504.

[22] D.R. McKenzie, Rep. Prog. Phys. 59 (1996) 1611.

[23] B.M. DeKoven, P.R. Ward, R.E. Weiss, D.J. Christie, R.A. Scholl, W.D. Sproul, F. Tomasel, A. Anders, 46th Annual Technical Conference of the Society of Vacuum Coaters, Society of Vacuum Coaters, San Francisco, CA, 2003, p. 158.

[24] M. Lattemann, A.P. Ehiasarian, J. Bohlmark, P.A.O. Persson, U. Helmersson, Surf. Coat. Technol. 200 (2006) 6495.

[25] A.P. Ehiasarian, J.G. Wen, I. Petrov, J. Appl. Phys. 101 (2007) 054301.

[26] K. Sarakinos, J. Wördenweber, F. Uslu, P. Schulz, J. Alami, M. Wuttig, Surface and Coatings Technology 202 (2008) 2323.

[27] J. Alami, P. Eklund, J.M. Andersson, M. Lattemann, E. Wallin, J. Bohlmark, P. Persson, U. Helmersson, Thin Solid Films 515 (2007) 3434.

[28] J.A. Davis, W.D. Sproul, D.J. Christie, M. Geisler, 47th Annual Technical Conference, Society of Vacuum Coaters, SVC, Dallas, TX, 2004, p. 215. 
[29] S. Konstantinidis, J.P. Dauchot, M. Hecq, Thin Solid Films 515 (2006) 1182.

[30] K. Sarakinos, J. Alami, M. Wuttig, J. Phys. D: Appl. Phys. 40 (2007) 2108.

[31] S. Konstantinidis, A. Hemberg, J.P. Dauchot, M. Hecq, J. Vac. Sci. Technol. B 25 (2007) L19.

[32] W.D. Sproul, D.J. Christie, D.C. Carter, 47th Annual Technical Conference, Society of Vacuum Coaters, SVC, Dallas, TX, 2004, p. 96.

[33] A.P. Ehiasarian, W.-D. Münz, L. Hultman, U. Helmersson, 45th Annual Techn. Conf. Procedings of the Society of Vacuum Coaters, Society of Vacuum Coaters, 2002.

[34] A.P. Ehiasarian, W.D. Munz, L. Hultman, U. Helmersson, I. Petrov, Surf. Coat. Technol. 163-164 (2003) 267.

[35] J. Alami, K. Sarakinos, F. Uslu, M. Wuttig, J. Phys. D: Appl. Phys. 42 (2009) 015304.

[36] P.E. Hovsepian, A.P. Ehiasarian, A. Deeming, C. Schimpf, Vacuum 82 (2008) 1312.

[37] K. Sarakinos, J. Alami, C. Klever, M. Wuttig, Surf. Coat. Technol. 202 (2008) 5033.

[38] V. Sittinger, F. Ruske, W. Werner, C. Jacobs, B. Szyszka, D.J. Christie, Thin Solid Films 516 (2008) 5847.

[39] R. Chistyakov, B. Abraham, W.D. Sproul, 49th Ann. Tech. Conf. Proc., Society of Vacuum Coaters, Washington, D.C., 2006, p. 88.

[40] J. Lin, J.J. Moore, W.D. Sproul, B. Mishra, J.A. Rees, Z. Wu, R. Chistyakov, B. Abraham, Surf. Coat. Technol. 203 (2009) 3676.

[41] S.M. Rossnagel, J. Vac. Sci. Technol. A 9 (1989) 261.

[42] I. Petrov, A. Myers, J.E. Greene, J.R. Abelson, J. Vac. Sci. Technol. A 12 (1994) 2846.

[43] B. Window, N. Savvides, J. Vacuum Sci. Technol. A 4 (1986) 504.

[44] J. Hopwood, F. Qian, J. Appl. Phys. 78 (1995) 758.

[45] M. Yamashita, Y. Setsuhara, S. Miyake, M. Kumagai, T. Shoji, J. Musil, Jpn. J. Appl. Phys. 38 (1999) 4291.

[46] J.M. Schneider, W.D. Sproul, A.A. Voevodin, A. Matthews, J. Vacuum Sci. Technol. A 15 (1997) 1084.

[47] W.M. Posadowski, Thin Solid Films 392 (2001) 201.

[48] Z.J. Radzimski, W.M. Posadowski, S.M. Rossnagel, S. Shingubara, J. Vac. Sci. Technol. B 16 (1998) 1102.

[49] S. Konstantinidis, J.P. Dauchot, M. Ganciu, A. Ricard, M. Hecq, J. Appl. Phys. 99 (2006) 013307.

[50] S.H.N. Lim, D.G. McCulloch, M.M.M. Bilek, D.R. McKenzie, J. Appl. Phys. 93 (2003) 4283.

[51] M.M.M. Bilek, D.R. McKenzie, Surf. Coat. Technol. 200 (2006) 4345.

[52] A. Anders, E.M. Oks, G.Y. Yushkov, J. Appl. Phys. 102 (2007) 043303. 


\section{Figure Caption}

Fig. 1 Schematic representation of a magnetron and its plasma (left); part of the plasma is available for PBII\&D processing of the substrate (right). In one configuration, the flow of ions can be further enhanced by ionizing the sputtered atoms with an RF coil (center); in another configuration, HIPIMS can be done 'gasless' in vacuum by initiating HIPIMS pulses with a short plasma from a cathodic vacuum arc source (center top). HIPIMS and bias pulses (and trigger plasma if applicable) can be synchronized. For more details see the text. 


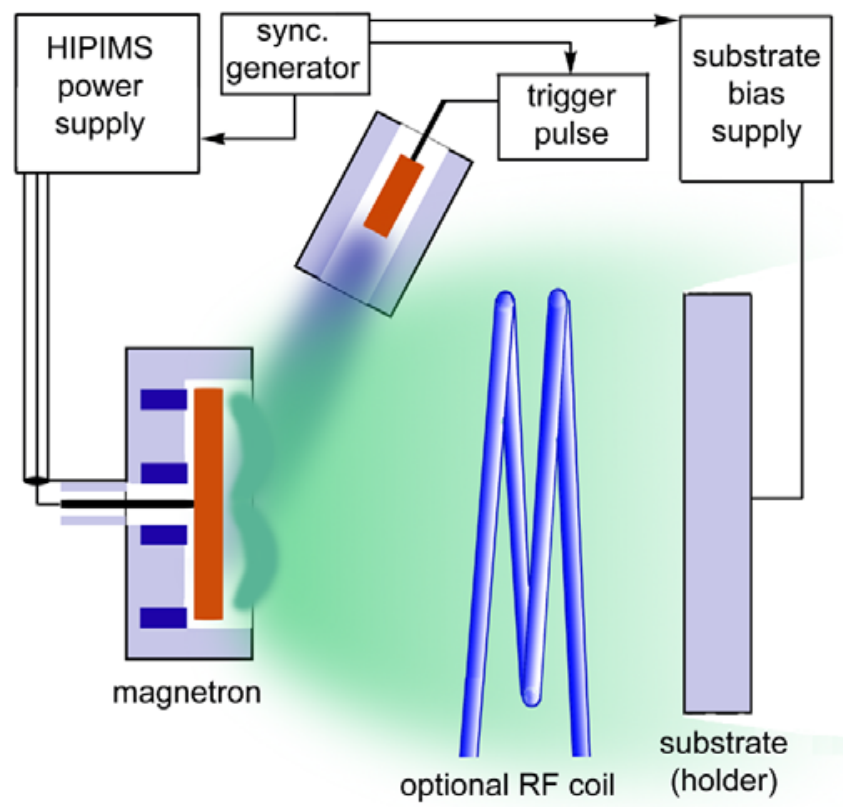

Fig. 1 